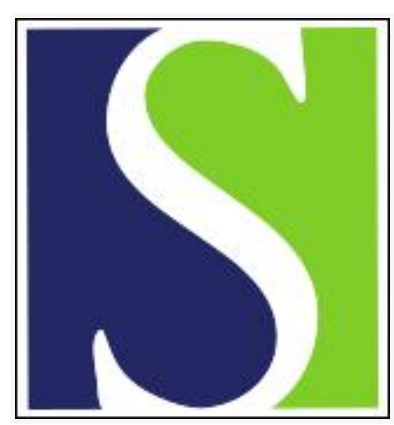

Scand J Work Environ Health 1984;10(1):7-16

https://doi.org/10.5271/sjweh.2361

Issue date: Feb 1984

Lung cancer mortality in a cohort of English foundry workers.

by Fletcher AC, Ades A

This article in PubMed: www.ncbi.nlm.nih.gov/pubmed/6740279

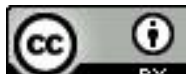

This work is licensed under a Creative Commons Attribution 4.0 International License 


\title{
Lung cancer mortality in a cohort of English foundry workers
}

\author{
by Antony C Fletcher, MSc, ${ }^{1}$ Anthony Ades, $\mathrm{PhD}^{2}$
}

\begin{abstract}
FLETCHER AC, ADES A. Lung cancer mortality in a cohort of English foundry workers. Scand $j$ work environ health 10 (1984) 7-16. A cohort of males who started work between 1946 and 1965 inclusive in nine English steel foundries and who worked in these foundries at least one year has been followed prospectively until 1978. Mortality from lung cancer was significantly raised among workers employed in the foundry and fettling shop areas (standardized mortality ratios 142 and 173, respectively). Most occupational categories in these two areas had more lung cancer deaths than expected, but the standardized mortality ratios were the largest for the furnace bricklayers, fettlers, and heat treatment furnacemen. There was some evidence of risk increasing with length of employment. There were marked differences in the standardized mortality ratio for lung cancer between study foundries. By year of entry the lung cancer risk was fairly constant, in contrast to the improvement in mortality from diseases of the respiratory system over the same period.
\end{abstract}

Key terms: foundry workers, lung cancer, mortality, retrospective cohort study, steel.

Since the earliest epidemiologic studies in the 1930s (38) a substantial body of epidemiologic evidence has accumulated which consistently suggests an increased risk of lung cancer associated with the foundry environment. Several reviews of the literature have been published $(16,30)$, the review by Tola $(36)$ dealing with the largest selection of the literature. The studies considered in the reviews include four cohort investigations, several census-based and case-referent studies, and one proportional mortality study. In addition the following investigations have been published: A Danish study of cancer incidence among foundry workers reported a standardized incidence ratio of $143(14)$, and Neuberger et al reported a standardized mortality ratio (SMR) of 173 for a cohort of Viennese foundry workers (26). Neither result was statistically significant. Blot et al's case-referent study (4) of lung cancer in the United States reported an odds ratio of 7.1 for foundry workers $(\mathrm{p}<0.05)$, a figure higher than the moderate odds ratios reported by Decoufle et al, ie, 1.37 for furnacemen, melters, and pourers and 1.51 for metal molders, both groups

\footnotetext{
1 Department of Environmental and Occupational Health, University of Aston in Birmingham, the United Kingdom.

2 TUC Centenary Institute of Occupational Health, London School of Hygiene and Tropical Medicine, the United Kingdom.
}

Reprint requests to: Mr AC Fletcher, Department of Environmental and Occupational Health, The University of Aston in Birmingham, Gosta Green, Birmingham B4 7ET, UK. employed at least five years (8). Kunze reported a significant $(\mathrm{p}<0.01)$ lung cancer odds ratio of 1.5 for "obtaining and working metal" in a case-referent study in Vienna (21).

The majority of previous studies did not distinguish type of foundry although iron foundries (the most common type) usually contributed the bulk of exposure. Where steel and other foundry employment could be distinguished, contradictory results emerged. Koskela et al reported an SMR of 151 for lung cancer in a cohort of foundry workers but an absence of lung cancer deaths in the steel foundry subcohort; however the numbers were very small (only 1.5 deaths expected in the group employed at least five years) (19). In Egan-Baum et al's proportional mortality study (proportional mortality ratio for lung cancer $=148, \mathrm{p}<0.001$ ) a case-referent study of lung cancer cases yielded an odds ratio of 1.26 for iron foundry employment when compared to steel foundry employment (10). On the other hand the cohort studies of steel foundry workers yielded results comparable to the risk estimates for all foundry workers or iron foundry workers $(15,32)$. Blot et al's case-referent study (4) derived an even higher risk estimate for steel foundry workers. A further problem shared by most of these studies was the small population sizes, particularly for steel foundry workers, and thus low power. A large retrospective cohort of steel foundry workers was therefore established. The results of a preliminary analysis of the lung cancer mortality are presented. 


\section{Subjects and methods}

\section{Subjects}

The Steel Castings Research and Trade Association (SCRATA) represents most steel foundries in the United Kingdom, its membership being responsible for approximately $90 \%$ of the volume of steel castings production. The foundries under investigation were drawn from SCRATA membership, and they comprised all those with sufficient personnel records and a willingness to cooperate with the study. This process yielded 10 foundries, substantially overrepresenting the larger foundries in the steel foundry industry of the United Kingdom. (They were all larger than the median size of the SCRATA foundries.) Further attempts to include smaller foundries to improve the representativeness of the sample were unsuccessful. Neither was the sample geographically representative, one-half of the study foundries being situated in Yorkshire, against $27 \%$ of SCRATA member foundries. One of the foundries was in Scotland, and it has not been considered in the present report. Results are presented for a population of workers from nine English steel foundries.

The cohort was defined as male employees who started work in the foundries between 1 January 1946 and 31 December 1965 and who were employed for at least one year. White-collar staff and management were excluded, as were the small number of women employed in the foundry manual jobs. For each individual who met the criteria, name, address, date of birth, national insurance number, and full occupational history were extracted from personnel or wages department records. Vital status was determined via the National Health Service Central Register for all those who were not still employed at the study foundries. For those untraced through the National Health Service records, information on vital status was sought from records of the Department of Health and Social Security. Table 1 shows the success of the tracing exercise as of 31 December 1978. Out of 10,250 cohort members, $2.3 \%$ were not traced, and their vital status was unknown. Another $1.7 \%$ had left the country. Of the 1,858 reported deaths, details of cause of death were unavailable for 14 at the time of the analysis. The analyses by length of employment and length of follow-up made use of the mor-

Table 1. Status of the cohort on 31 December 1978.

\begin{tabular}{lc}
\hline Status & $\mathrm{N}$ \\
\hline Traced and alive & 7,988 \\
Traced and dead & 1,858 \\
Emigrated & 173 \\
Untraced & 231 \\
\hline Total & 10,250 \\
\hline
\end{tabular}

tality up to December 1980 , by which time 2,105 of the cohort members had died and the proportion untraced had fallen to $1.8 \%$.

\section{Methods}

Expected deaths were calculated through the application of national (England and Wales) death rates to the person-years accumulated in five-year age and calendar periods; the Man Years Computer Language program was used (17). Person-years were accumulated from the end of the one-year qualification period up to the end of 1978 (or 1980) or until loss to followup. The total accumulated by the population up to 31 December 1978 was 203,070 person-years. Cause of death was coded according to the Eighth Revision of the International Classification of Diseases (ICD), and the death rates, adjusted (by the Medical Statistics Survey Unit of the Health and Safety Executive) to the Eighth Revision, were used as the basis for comparison. The SMRs were calculated, and they have been used as the summary statistic in this study. The statistical significance of the SMRs was evaluated by chi-squared tests, except where less than 20 deaths were observed, in which case the Poisson distribution was used ( $p$-values refer to two-tailed tests). Chisquared tests for trend and homogeneity were also carried out (31).

Observed and expected deaths were calculated and subdivided by foundry, occupational category, and five-year entry cohort. The occupational categories, as explained in the next section, conveniently aggregated into three work areas and provided sufficient numbers to allow analysis by length of employment and length of follow-up. The latter analyses were performed slightly later, and they allowed deaths occurring up to the end of 1980 to be used. However, for the 1,816 study members who were employed in 1978 and who were not sent for tracing, the subsequent status was unknown. They contributed to the personyears, and thus to the calculation of expected deaths, only up to 1978. Observed and expected deaths occurring in 1979 and 1980 and included in the analysis by length of employment were thus restricted to those who had already left foundry work. The average age was lower for those still employed than for the cohort as a whole, and expected deaths for the 1,816 individuals still employed in 1978, if followed for a further two years, would add less than $1 \%$ to the lung cancer deaths already accumulated. Thus the bias introduced by only including deaths, in 1979 and 1980 , of those who had left is small. The effect of the inclusion of 1979/1980 deaths was to raise the SMR slightly for the foundry group and lower it for the fettling shop group. (Compare tables 4 and 6 in the Results section.) SMRs by work area and length of employment were further analyzed with the Generalised Linear Interactive Modelling (GLIM) package (2) according to the method described by Berry (3). 
The method assumes additivity in the logarithms of relative risk. Essentially, various regression models are fitted by maximum likelihood estimation, the logarithm of observed/expected deaths in each group being predicted from the occupational category and median years employed.

\section{Occupational categories}

From discussions with personnel officers individual occupational titles were grouped into 25 occupational categories. These categories were then aggregated into the following three work areas: the foundry, the fettling shop, and work stations outside these two areas. In the foundry itself sand is prepared and formed into molds and cores. Steel is melted in a furnace and transferred by ladle to be cast into molds. After setting, the mold is "knocked-out" to reveal the casting. Whereupon it is transferred to the fettling shop, where, after shotblast cleaning, excess metal and any burnt-on sand are removed by cutting torches, pneumatic chisels, and high speed grinding. The casting may then be repaired by welders or subjected to heat treatment. The "other occupations" outside the foundry and fettling shop comprised mainly turners, millers and laborers in the machine shop, the pattern shop where wooden patterns are made for the molding operation, maintenance fitters and their mates, and various outside jobs such as truck driving. Although the maintenance workers may be exposed from time to time to fettling shop and foundry conditions, and most of the categories may face some hazardous occupational exposures, the "other" group may be considered largely nonexposed to conditions in the foundry and fettling shop.

For the purpose of analysis each individual in the cohort was uniquely assigned to the occupational category which he occupied for the greatest proportion of time during his employment in the study foundries. While there was some movement between occupational categories, it occurred only for a small minority of the cohort and was largely within a particular work area.

\section{Results}

\section{All causes of death}

Table 2 gives the observed and expected number of deaths and the SMRs by the three work areas. Results are presented for all causes of death, all cancers, diseases of the respiratory system, and diseases of the circulatory system. The slight excesses of observed deaths in the foundry and fettling shop were more than accounted for by mortality from cancers and diseases of the respiratory system. Within the latter category much of the excess could be ascribed to high mortality from chronic bronchitis (foundry SMR 149 , fettling shop SMR 185). Deaths from diseases of the circulatory system were close to the expected number.

It is not uncommon for industrial cohorts to exhibit SMRs that are below 100 because of the "healthy worker effect," whereby people who are unfit for work are excluded from the cohort yet are represented in the numerator of national mortality statistics against which comparisons are made (13). This selection process may be expected to have more effect where the work is physically strenuous, as is the case in many foundry and fettling shop occupations. Analysis of mortality by length of time from first employment confirmed that indeed this effect took place in the cohort included in our study. The SMRs for deaths (all causes) within five years of commencing employment were 81 for the foundry, 67 for the fettling shop, and 96 for the other jobs group.

Table 3 presents the mortality by age at death for the foundry and fettling shop groups combined. The excess for all causes was found to be the highest in the 50- to 59-year age group. Where total mortality was subdivided by individual occupational category, only two yielded significantly high SMRs, ie, the furnace repair men (SMR 140) and the fettlers (SMR 117).

The excess of mortality from cancer for the workers in the foundry and fettling shop (table 2) was more than accounted for by the excess deaths from lung and stomach cancer. Mortality from stomach cancer was slightly but not significantly raised for the fettling

Table 2. Mortality by work area - All deaths and deaths from cancer, diseases of the respiratory system, and diseases of the circulatory system. (Obs = observed deaths, Exp = expected deaths, SMR = standardized mortality ratio)

\begin{tabular}{|c|c|c|c|c|c|c|c|c|c|c|c|c|}
\hline \multirow{3}{*}{ Work area } & \multicolumn{12}{|c|}{ Cause of death ${ }^{\mathrm{a}}$} \\
\hline & \multicolumn{3}{|c|}{$\begin{array}{l}\text { All causes } \\
(000-999)\end{array}$} & \multicolumn{3}{|c|}{$\begin{array}{c}\text { All cancers } \\
(140-239)\end{array}$} & \multicolumn{3}{|c|}{$\begin{array}{l}\text { Diseases of the } \\
\text { respiratory system } \\
(460-519)\end{array}$} & \multicolumn{3}{|c|}{$\begin{array}{l}\text { Diseases of the } \\
\text { circulatory system } \\
(390-458)\end{array}$} \\
\hline & Obs & Exp & SMR & Obs & $\operatorname{Exp}$ & SMR & Obs & Exp & SMR & Obs & Exp & SMR \\
\hline Foundry & 815 & 766.2 & 106 & 244 & 195.1 & $125^{* \star *}$ & 124 & 94.2 & $132^{* *}$ & 342 & 362.1 & 95 \\
\hline Fettling shop & 392 & 354.9 & 110.5 & 109 & 92.1 & 118 & 72 & 40.3 & $179^{* * *}$ & 161 & 166.5 & 97 \\
\hline Other jobs & 643 & 634.4 & 101.4 & 154 & 159.3 & 97 & 101 & 81.3 & $124^{\star}$ & 317 & 300.6 & 105.5 \\
\hline
\end{tabular}

a Code of the International Classification of Diseases in parentheses.

${ }^{*} p<0.05,{ }^{* *} p<0.01,{ }^{* * *} p<0.001$. 
shop group (13 observed, 10.2 expected) but was significantly raised for the foundry group (42 observed, 22.4 expected). Excess cancer mortality among the workers employed in the foundry and fettling areas

Table 3. Mortality by age from all causes and lung cancer for the foundry/fettling shop populations. (SMR = standardized mortality ratio, Obs = observed)

\begin{tabular}{crcrrr}
\hline \multirow{2}{*}{ Age group } & \multicolumn{2}{c}{ All causes } & & \multicolumn{2}{c}{ Lung cancer } \\
\cline { 2 - 3 } \cline { 5 - 6 } & SMR & Obs deaths & & SMR & Obs deaths \\
\hline $15-39$ & 83 & 61 & & 87 & 2 \\
$40-49$ & 106 & 175 & & 166 & $24^{*}$ \\
$50-59$ & 121 & $390^{* * *}$ & & 171 & $73^{* * *}$ \\
$60-69$ & 104 & 371 & & 121 & 54 \\
$\geq 70$ & 103 & 210 & & 189 & $28^{* * *}$ \\
\hline All ages & 108 & $1,207^{* *}$ & & 152 & $181^{* * *}$ \\
\hline
\end{tabular}

* $p<0.05, \quad{ }^{\star *} p<0.01, \quad{ }^{* \star *} p<0.001$. was, in the main, from lung cancer, the analysis of which forms the bulk of this report.

\section{Lung cancer}

Tables 4 and 5 present the mortality from malignant neoplasms of the trachea, bronchus, and lung (ICD code 162 , hereafter referred to as lung cancer) subdivided by work area and those individual occupational categories yielding at least five lung cancer deaths. By work area, the SMRs were both highly significant for the foundry (SMR 142) and fettling shop (SMR 173). The SMRs for four individual occupations achieved statistical significance: furnace repairmen who remove, repair, and replace the refractory brick linings in the steel melting furnaces; fettlers and grinders of castings; heat treatment furnacemen; and, in the other jobs group, the maintenance fitters' mates. Within the foundry and fettling shop groups, there was a consistency between jobs, excess mor-

Table 4. Mortality from lung cancer by occupational category - Foundry and fettling shop occupations.

\begin{tabular}{|c|c|c|c|c|}
\hline Occupation & $\begin{array}{l}\text { Observed } \\
\text { deaths }\end{array}$ & $\begin{array}{l}\text { Expected } \\
\text { deaths }\end{array}$ & $\begin{array}{l}\text { Standardized } \\
\text { mortality ratio }\end{array}$ & $\begin{array}{c}95 \% \text { confidence } \\
\text { interval }\end{array}$ \\
\hline \multicolumn{5}{|l|}{ Foundry } \\
\hline Sand millers & 6 & 4.1 & 147 & $54-321$ \\
\hline Molders and coremakers & 17 & 13.5 & 126 & $85-220$ \\
\hline Furnacemen and casters & 17 & 13.7 & 124 & $72-199$ \\
\hline Furnace repair & 19 & 9.4 & $203^{* *}$ & $122-317$ \\
\hline Laborers & 41 & 29.6 & 139 & $100-188$ \\
\hline Knock out & 5 & 2.9 & 174 & $56-405$ \\
\hline Crane drivers & 7 & 5.6 & 124 & $50-256$ \\
\hline Remainder & 3 & 2.2 & 139 & $29-406$ \\
\hline All foundry occupations & 115 & 80.8 & $142^{* \star *}$ & $118-172$ \\
\hline \multicolumn{5}{|l|}{ Fettling shop } \\
\hline Shot blasters & 6 & 3.2 & 191 & $70-415$ \\
\hline Fettlers and grinders & 32 & 16.4 & $195^{* * *}$ & $134-276$ \\
\hline Welders & 8 & 5.5 & 146 & $62-288$ \\
\hline Heat treatment & 8 & 2.3 & $356^{*}$ & $154-701$ \\
\hline Laborers & 5 & 6.5 & 78 & $25-181$ \\
\hline Remainder & 7 & 4.3 & 163 & $65-335$ \\
\hline All fettling shop occupations & 66 & 38.2 & $173^{* * *}$ & $134-221$ \\
\hline All foundry/fettling occupations & 181 & 119.0 & $152^{* * *}$ & $13 \uparrow-176$ \\
\hline
\end{tabular}

${ }^{*} p<0.05,{ }^{* *} p<0.01,{ }^{* * *} p<0.001$.

Table 5. Mortality from lung cancer by occupational category - Occupations outside the foundry and the fettling shop.

\begin{tabular}{lcccc}
\hline Occupation & $\begin{array}{c}\text { Observed } \\
\text { deaths }\end{array}$ & $\begin{array}{c}\text { Expected } \\
\text { deaths }\end{array}$ & $\begin{array}{c}\text { Standardized } \\
\text { mortality ratio }\end{array}$ & $\begin{array}{c}95 \% \text { confidence } \\
\text { interval }\end{array}$ \\
\hline Machinists & 19 & 12.0 & 158 & $95-247$ \\
Machine shop laborers & 19 & 16.6 & 115 & $69-179$ \\
Maintenance fitters & 7 & 10.6 & 66 & $27-136$ \\
Maintenance fitters' mates & 17 & 7.6 & $225^{*}$ & $131-360$ \\
Remainder & 10 & 19.0 & 53 & $24-221$ \\
\hline All nonfoundry/fettling & 72 & 65.7 & 110 & $86-139$ \\
\hline
\end{tabular}

** $p<0.01$. 
tality being found in virtually all the occupational categories $\left(p>0.1, \chi^{2}\right.$ test of homogeneity for both groups). The hypothesis of homogeneity was rejected for the other jobs group $(\mathrm{p}<0.001)$.

These and the other analyses were carried out on data from the nine foundries aggregated together. There were however marked differences for lung cancer mortality between foundries $\left(p<0.01, \chi_{8}^{2}=\right.$ 22.6). One foundry population had a significantly low lung cancer mortality (one observed death, 8.2 expected), and among the rest the SMRs were in the range of 84 to 182 , though the three SMRs less than 100 were all in the smaller foundries and thus contributed relatively little to the aggregate data. Correcting for region had very little impact on the degree of variation.

The data for lung cancer mortality subdivided by age at death are presented in table 3 , and the SMRs show a bimodal distribution with most of the excess deaths occurring in the 40- to 59-year age group, but a further excess in the $\geq 70$-year age group.

Figure 1 presents SMRs (and their confidence intervals) for lung cancer by cohort of entry for the

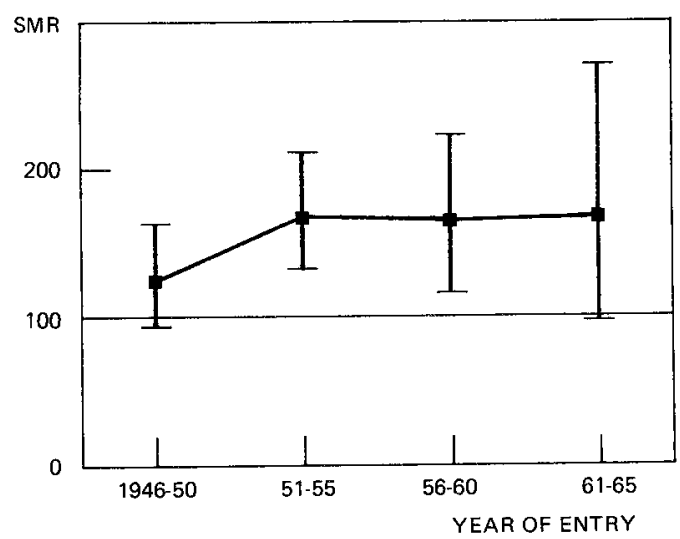

Figure 1. Standardized mortality ratio and $95 \%$ confidence interval for lung cancer by year of commencing employment, in five-year periods, for the foundry and fettling shop workers combined. foundry and fettling areas combined. The results show that the SMR appears to be independent of the date of starting work in the foundry in spite of the shorter period of follow-up for later entrants. The findings are in marked contrast with the data for mortality from diseases of the respiratory system, presented in figure $2\left(\chi^{2}\right.$ for trend $\left.=10.6, \mathrm{p}<0.001\right)$.

Table 6 presents the SMRs (and the observed number of deaths on which they were based) for lung cancer deaths in each work area, subdivided by years since employment commenced in the study foundries. The mortality in the first $\mathbf{1 0}$ years of follow-up was lower than subsequently for the other jobs group though not so consistently for the foundry and fettling shop groups. Because lung cancer deaths less than 10 years since employment commenced would almost certainly be independent of that employment, analysis by length of employment was restricted to deaths after 10 years' follow-up.

Observed and expected deaths by length of employment are presented in table 7 , and the relationships between the SMR and length of employment are illustrated in figure 3, as SMRs for lung cancer with

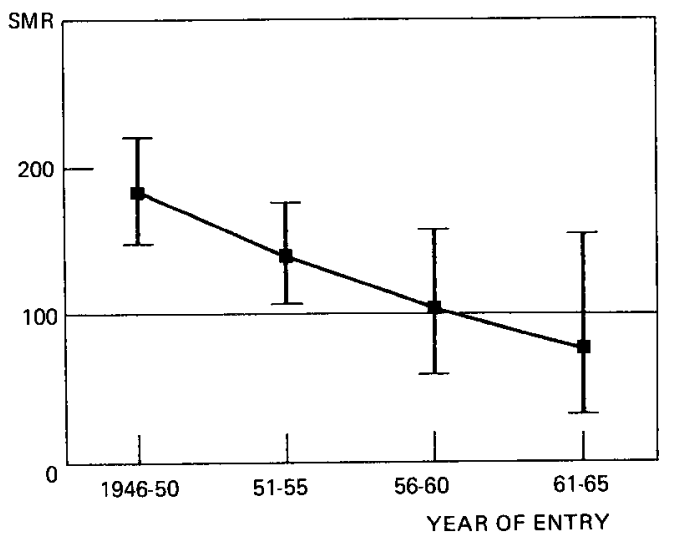

Figure 2. Standardized mortality ratio and $95 \%$ confidence interval for diseases of the respiratory system by year of commencing employment, in five-year periods, for the foundry and fettling shop workers combined.

Table 6. Lung cancer mortality by length of follow-up from entering study. (SMR $=$ standardized mortality ratio, Obs $=$ observed)

\begin{tabular}{|c|c|c|c|c|c|c|c|c|c|c|c|c|c|c|}
\hline \multirow{3}{*}{ Work area } & \multicolumn{12}{|c|}{ Years since commencement of employment } & \multirow{2}{*}{\multicolumn{2}{|c|}{ Total }} \\
\hline & \multicolumn{2}{|c|}{$1-4$} & \multicolumn{2}{|c|}{$5-9$} & \multicolumn{2}{|c|}{$10-14$} & \multicolumn{2}{|c|}{$15-19$} & \multicolumn{2}{|c|}{$20-24$} & \multicolumn{2}{|c|}{$\geq 25$} & & \\
\hline & SMR & $\begin{array}{l}\text { Obs } \\
\text { deaths }\end{array}$ & SMR & $\begin{array}{l}\text { Obs } \\
\text { deaths }\end{array}$ & SMR & $\begin{array}{l}\text { Obs } \\
\text { deaths }\end{array}$ & SMR & $\begin{array}{l}\text { Obs } \\
\text { deaths }\end{array}$ & SMR & $\begin{array}{c}\text { Obs } \\
\text { deaths }\end{array}$ & SMR & $\begin{array}{l}\text { Obs } \\
\text { deaths }\end{array}$ & SMR & $\begin{array}{l}\text { Obs } \\
\text { deaths }\end{array}$ \\
\hline Foundry & 123 & 7 & 162 & 18 & 128 & 21 & 166 & 33 & 133 & 26 & 155 & 30 & 147 & 135 \\
\hline $\begin{array}{l}\text { Fettling } \\
\text { shop }\end{array}$ & 176 & 4 & 42 & 2 & 262 & 20 & 197 & 15 & 163 & 16 & 137 & 13 & 161 & 70 \\
\hline $\begin{array}{l}\text { Foundry \& } \\
\text { fettling } \\
\text { shop }\end{array}$ & 138 & 11 & 125 & 20 & 171 & 41 & 163 & 48 & 143 & 42 & 149 & 43 & 151 & 205 \\
\hline $\begin{array}{l}\text { Other } \\
\text { jobs }\end{array}$ & 72 & 4 & 105 & 11 & 131 & 19 & 112 & 18 & 104 & 15 & 103 & 14 & 109 & 81 \\
\hline
\end{tabular}




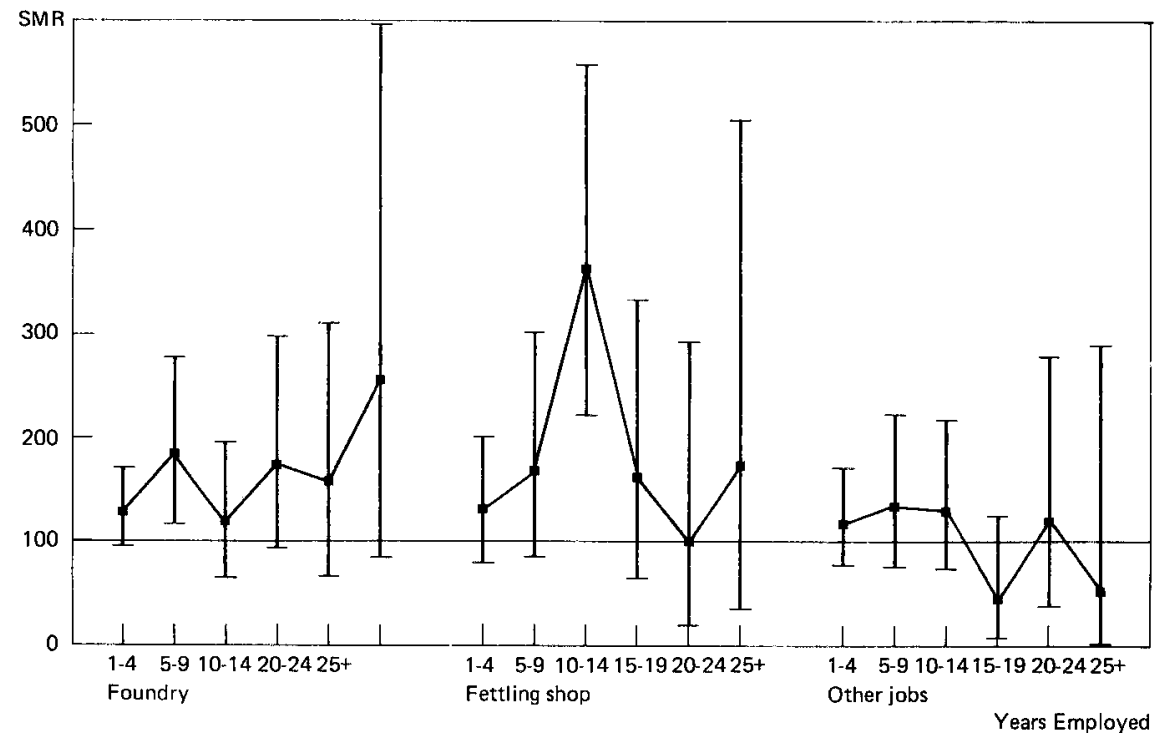

Figure 3. Standardized mortality ratio and $95 \%$ confidence interval for lung cancer by years of employment and work area (from data in table 7).

Table 7. Lung cancer mortality by length of employment and work area - Observed (Obs) and expected (Exp) deaths more than 10 years after the commencement of employment.

\begin{tabular}{|c|c|c|c|c|c|c|c|c|c|c|c|c|c|c|}
\hline \multirow{3}{*}{ Work area } & \multicolumn{12}{|c|}{ Years employed } & \multirow{2}{*}{\multicolumn{2}{|c|}{ Total }} \\
\hline & \multicolumn{2}{|c|}{$1-4$} & \multicolumn{2}{|c|}{$5-9$} & \multicolumn{2}{|c|}{$10-14$} & \multicolumn{2}{|c|}{$15-19$} & \multicolumn{2}{|c|}{$20-24$} & \multicolumn{2}{|c|}{$\geq 25$} & & \\
\hline & Obs & Exp & Obs & Exp & Obs & $\operatorname{Exp}$ & Obs & Exp & Obs & Exp & Obs & Exp & Obs & Exp \\
\hline Foundry & 46 & 35.7 & 23 & 12.5 & 15 & 12.6 & 13 & 7.4 & 8 & 5.1 & 5 & 2 & 110 & 75.2 \\
\hline $\begin{array}{l}\text { Fettling } \\
\text { shop }\end{array}$ & 20 & 15.3 & 11 & 6.6 & 20 & 5.5 & 7 & 4.3 & 3 & 3.0 & 3 & 1.7 & 64 & 36.5 \\
\hline Other jobs & 27 & 22.9 & 15 & 11.1 & 15 & 11.3 & 3 & 7.1 & 5 & 4.2 & 1 & 1.9 & 66 & 58.5 \\
\hline
\end{tabular}

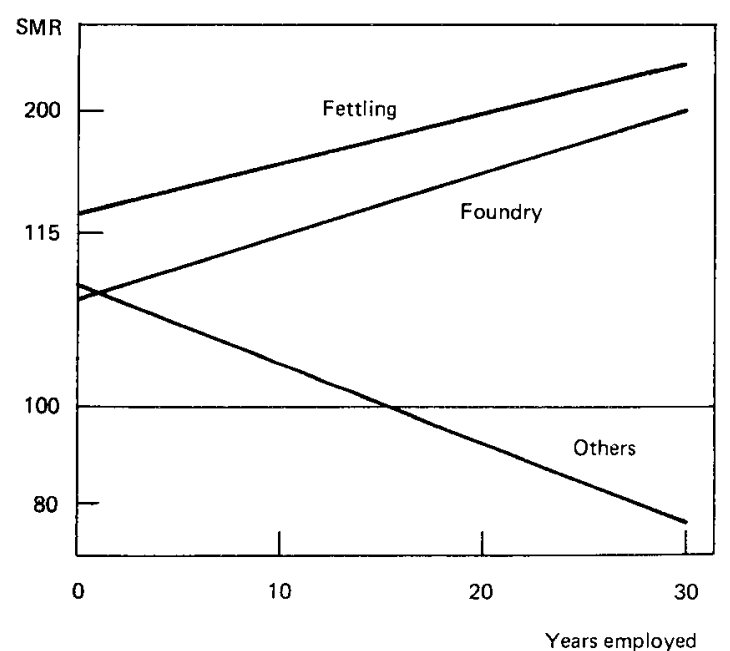

Figure 4. Regression of the standardized mortality ratio for lung cancer (log scale) for each work area on years of employ. ment. confidence intervals for each work area. The SMRs for foundry and fettling shop workers employed less than five years was lower than for those employed five years or more, and this comparison was statistically significant when the two groups were combined. However, as figure 3 shows, the pattern of SMRs by length of employment was not clear; to investigate underlying trends, we analyzed the observed and expected deaths in table 7 using GLIM.

Figure 4 shows the regression of the SMR (log scale) against years employed for each work area, on the assumption of a model in which each occupational group can have a different slope and intercept. The foundry and fettling shop groups appear to have increasing risk with length of service, while the other jobs group has a decreasing risk. However none of these three slopes was statistically different from zero at the $5 \%$ level. [The standard normal deviates (SNDs) were foundry 1.14 , fettling 0.79 , others 1.05 .] Furthermore, with this model, there was no evidence 
that the three groups had different risks at zero year's employment $\left(\chi^{2}=0.59\right)$. This finding suggests that such differences as there were between occupational groups did not exist prior to work in the study foundries.

Rather than compare each slope in figure 4 with zero, it is instructive for one to take the "other jobs" category as a reference group and test for differences between it and the two exposed groups. In a model specifying equal risks "at entry", the differences in slopes between the exposed and nonexposed groups were statistically large (foundry-other jobs SND = 2.23, $\grave{\mathrm{p}}<0.05$; fettling-other jobs SND $=2.27$, $p<0.01$ ). If different risks "at entry" are allowed in the model, the differences in slope are not statistically significant (foundry-other jobs SND $=1.52$; fettling-other jobs SND $=1.31$ ) .

\section{Discussion}

The elevated lung cancer mortality in the foundry and fettling shop occupations does not appear to be associated with any particular occupational category. Several SMRs for particular occupations were somewhat higher than the total SMR for each work area and some of the occupations in question were particularly dusty - fettling, shotblasting, knock out, and furnace repair. The finding for heat treatment furnacemen (SMR 356) has not been previously reported and is not regarded as a foundry occupation with any exceptional environmental exposure. Maintenance fitters' mates may spend some time in the foundry and fettling areas but then so do the maintenance fitters themselves, who had low lung cancer mortality. The relative homogeneity of risk across the job categories suggests common factors for the etiology of these foundry workers' lung cancer.

The lung cancer SMR of 152 for the foundry and fettling shop groups combined is broadly consistent with the findings of several other cohort studies of foundry workers. SMRs in two cohorts of steel foundry workers in Canada (15) and the United States (32) were 250 and 201, respectively. Foundry cohort studies in America (9), Austria (26), and Finland (19) have reported lung cancer SMRs in the range of 126 to 173. In addition, England and Wales census-based mortality ratios have consistently been in the range of 140 to 200 for foundry occupations $(28,33)$ even though the studies are not strictly comparable because of differences in cohort definition and period of follow-up, as well as foundry type and period studied. The narrowness of the range of most of the risk estimates, approximately 1.5 to 2.5 , is striking, as is the fact that, of 12 investigations from which relative risks for lung cancer might be estimated for foundry workers, none of the risk estimates were close to or less than unity (though several were not significantly elevated). Several cohort studies provided analysis by occupational categories. Aside perhaps from Gibson et al's data for crane drivers in a steel foundry (SMR 714 , four observed deaths) the risk estimates by occupational category from previous studies $(15,22$, 37 ) are generally consistent (if only because they all have fairly wide confidence intervals) with our findings.

The risk of dying from respiratory disease, briefly referred to in this paper, was found to drop sharply over time in the analysis by entry cohort shown in figure 3. (The gradient was in fact steepest for fettling shop workers.) This phenomenon would be expected, as the period covered by the present study was the period when efforts were being made to reduce siliceous dust exposure in foundries. By contrast, the risk of dying of lung cancer was fairly constant over the five-year entry cohorts. The same period has been one of great technological development in the foundry industry. Traditionally, the sand in molds was bound by a mixture involving clay and organic additives (such as pitch, flour, or coal dust). These materials have been increasingly replaced over the last 30 years with chemical systems making use of phenol, formaldehyde, isocyanates, furfuryl alcohol, amine catalysts, and many other materials. None of the published epidemiologic studies have attempted to correlate binder usage with mortality patterns, though such a correlation is being undertaken in the update of the current study.

In our attempt to establish a dose-response relationship, length of employment had to be used as a surrogate of dose because no hygiene measurements were available from the foundries during the period of study. (However, it is not clear exactly what hygiene measurements would be appropriate.) Length of employment is a poor surrogate for dose because rates of exposure may have fallen as ventilation and personal protective equipment usage increased and the nature of the exposure underwent qualitative changes. Furthermore there are a number of factors which serve to obscure any positive association with length of employment.

While ignoring the first 10 years' follow-up serves to avoid the effects of initial health selection, selective withdrawal of sick people, leaving a healthier "survivor population" still employed, can depress the mortality of those who work the longest. Fox \& Collier (12) reported this effect as being more marked for lung cancer than circulatory or respiratory diseases in their study of polyvinyl chloride workers. In addition the heterogeneity of the foundry and fettling shop groups could potentially lead to the same pattern; the occupations with the higher mortality ratios also had smaller mean lengths of employment and were thus underrepresented in the longer employment categories. For example $26 \%$ of the fettling shop population worked at least 15 years, yet only $16 \%$ of the heat treatment workers were employed this long. Koskela et al (20), in their study of turnover among foundry workers, reported higher turnover rates for 
workers in dustier occupations. It is processes such as these that may explain the negative slope with length of employment in the occupations outside the foundry and fettling areas (figure 4). If one assumes that this mechanism is operating to a similar degree in the foundry and fettling shop groups, then the difference in gradients from that of the other jobs category would estimate the underlying association with length of employment and would therefore control for such a selection mechanism. These steeper gradients were however only significant in the model where all the difference in risk between the three groups was explained by the relationships with length of employment. The comparison of more than five years' employment with less than five years' employment to some extent avoids the problems outlined because the bulk of the population worked less than 15 years, and a positive association with length of employment was indicated.

It is likely that a substantial fraction of this population will have been employed at other times in their work lives in other foundries, and thus the length of employment as reported is a poor measure of true duration of foundry employment. The elevated lung cancer risk reported may thus be in part due to previous employment. Further work is seeking to evaluate the importance of previous employment and the selective factors already discussed.

\section{Potential confounding factors}

Expected deaths were derived from the application of death rates for England and Wales to the personyears at risk for the cohort; however, five of the nine foundries were located in Yorkshire, a region of slightly higher than average lung cancer mortality. To give some estimate of the bias introduced by the use of national death rates, mortality ratios for each foundry were recalculated through the adjustment of the number of expected deaths. In each case the number of expected deaths was multiplied by the appropriate regional mortality ratio (for ages 15-64 years) for the years 1970-1972. This procedure should have given a reasonable estimate because 1970-1972 was coincident with the median of the calendar distribution of observed deaths and the age structure of the lung cancer deaths below age 65 approximated the national distribution. The application of these adjustments reduced the SMR for lung cancer for the entire cohort from 139 to 131 , a fairly minimal change.

Smoking is a potent cause of lung cancer, but no data on the smoking habits of the cohort were collected; thus the contribution of smoking to the excess lung cancer mortality could not be evaluated. If smoking were to account for the raised SMRs reported, then the smoking habits of the foundry workers would have had to differ markedly from the national rates. Axelson (1) estimated that, compared to a reference population of whom $50 \%$ were smokers, to account for risk ratios of 1.4 and 1.8 , the proportion of smokers in the study group would have to be 70 and $90 \%$, respectively. The average prevalence of cigarette smoking among males in Britain during the period of this study was higher than $50 \%$, dropping from approximately $70 \%$ in 1946 to $50 \%$ in 1974 (5). To account for the SMRs found in this study, virtually all the study population would have had to smoke cigarettes; yet there was no evidence to suggest that this may have been the case. Furthermore the smoking habits hardly differed across social class in the 1950 s, unlike today when manual workers smoke more than nonmanual workers (34).

Three studies have reported prevalences of cigarette smoking among foundry workers. A random sample of 156 foundry workers in a Derbyshire town in 1957 contained, in the 25- to 34-year age group, $67 \%$ smokers, against $73 \%$ for other men in the town, and for the 55- to 64-year age group there were $65 \%$ smokers against $59 \%$ for other men $(6,7)$. At that time tobacco industry surveys estimated that $60 \%$ of adult males smoked manufactured cigarettes, excluding hand-rolled cigarettes (5). In 1964 a random sample of 1,997 foundry workers aged 35-64 years were compared to 1,777 engineering workers in nearby factories (23). The prevalences for smoking were 73.9 and $70.4 \%$, respectively. These figures compare with those of two national surveys reporting prevalences of 68 and $71 \%$ for adult male smokers in 1965 $(25,27)$. A national survey in 1972 included 103 men classified as furnace, forge, foundry, and rolling mill workers, of whom $62 \%$ smoked against $54 \%$ for the survey as a whole (28). Gibson et al (15) in Canada and Koskela et al (19) in Finland both reported no significant difference in smoking habits between current foundry workers and nonfoundry worker referents in the cohorts they studied. In summary, there is no evidence that foundry workers' smoking habits differ markedly from the general population. The best estimate of past smoking habits derives from the 1964 sample of foundry workers, in which about $3 \%$ more than the average were smokers.

Neuberger's cohort study (26) of dust-exposed workers, of which foundry workers were the largest subgroup, had an SMR of 173 for lung cancer in comparison to 113 for the reference group, which was matched for smoking habits. Three lung cancer casereferent studies adjusted for smoking in the analysis. Kunze's study in Vienna (21) reported a smokingadjusted odds ratio of 1.5 for metal workers, and, in Decoufle et al's study (8), adjustment for smoking decreased the odds ratio slightly for furnacemen and increased it for molders. In Blot et al's recent study (4), adjustment for smoking reduced the odds ratio for steelworkers from 2.2 to 1.9 .

In the present study, observed lung cancer deaths were overall fairly close to the expected number for 
the occupations outside the fettling and foundry areas. These people were from the same geographic areas (and social class categories) as the foundry and fettling shop workers and may be expected to have had similar smoking habits. In addition, deaths from ischemic heart disease, another consequence of cigarette smoking, were about $10 \%$ below expected for the foundry and fettling shop workers. The evidence from other studies suggests that there are no strong grounds for asserting that foundry and fettling shop workers smoke sufficiently more than the national average to account for the raised lung cancer mortality reported, though in the absence of smoking data this cannot be entirely ruled out.

\section{Conclusion}

The present study has confirmed earlier reports that foundry work is associated with an increased risk of lung cancer. There is some evidence of a relationship with length of employment for the workers employed in the fettling shop area and to a lesser extent the foundry itself. The excess is unlikely to be due to smoking.

Recent studies have identified known carcinogens in the foundry environment $(11,29,35,37,39)$ and mutagenic activity of foundry fumes $(16,18,24)$, though it is not known whether the levels of exposures reported would have been sufficient to result in the risk of lung cancer reported in the present communication. It would however be prudent to strengthen efforts to reduce exposure to all fumes and dusts in the foundry, particularly where binder pyrolysis products may be present.

Currently the mortality of the cohort described is being updated and further analyzed. Other causes of death, including stomach cancer, will be considered in detail. Attempts are being made to quantify the role of smoking and previous occupation as potential confounders, and past exposures in these foundries are being estimated. Drs Levy and Martin of this Department are currently carrying out a bioassay of foundry fumes by intrabronchial implantation in rats.

\section{Acknowledgments}

We would like to thank the Steel Castings Research and Trade Association (SCRATA) for its financial support of the project, Mr G Lucas, SCRATA staff, and employees in each of the foundries for help with the data collection, Professor MA Cooke, and Professor AJ Fox. Mr MR Phillips and Dr JAH Waterhouse provided guidance in the design and analysis of the project, for which we are very grateful.

\section{References}

1. Axelson $O$. Aspects of confounding and effect modification in the assessment of occupational cancer risk. $J$ toxicol environ health 6 (1980) 1127-1131.

2. Baker RJ, Nelder JA. The GLIM system - Release 3, general linear interactive modelling. Numerical Algorithms Group, Oxford 1978.

3. Berry $G$. The analysis of mortality by the subject-years method. Biometrics 39 (1983) 173-184.

4. Blot WJ, Brown LM, Pottern LM, Stone BJ, Fraumeni JF. Lung cancer mortality among long-term steel workers. Am j epidemiol 117 (1983) 706-716.

5. Capell PJ. Trends in cigarette smoking in the United Kingdom. Health trends 10 (1978) 49-54.

6. Cochrane AL, Moore F. A 20-year follow-up of men aged 55-64 including coal-miners and foundry workers in Stavely, Derbyshire. Br j ind med 37 (1980) 226229.

7. Cochrane AL, Moore F. A 20-year follow-up of a population sample (aged 25-34) including miners and foundry workers in Stavely, Derbyshire. $\mathrm{Br} \mathrm{j}$ ind med 37 (1980) 230-233.

8. Decoufle P, Stanislawczyk K, Honten L, Bross IDJ, Viadana E. A retrospective survey of cancer in relation to occupation. US Department of Health Education and Welfare, Cincinnati, $\mathrm{OH} 1977$.

9. Decoufle P, Wood DJ. Mortality patterns among workers in a gray iron foundry. Am j epidemiol 109 (1979) 667-675.

10. Egan-Baum E, Miller BA, Waxweiler RJ. Lung cancer and other mortality patterns among foundrymen. Scand j work environ health 7 (1981): suppl 4, 147155.

11. Fajen JM, Rounbehler DP, Fine DH. Summary report on n-nitrosamines in the factory environment. In: Bartsch H, Castegnaro M, O’Neill IK, Okada M, ed. $\mathrm{N}$-nitroso compounds: Occurrence and biological effects. International Agency for Research on Cancer, Lyon 1982.

12. Fox AJ, Collier PF. Low mortality rates in industrial cohort studies due to selection for work and survival in industry. Br j prev soc med 30 (1976) 225-230.

13. Fox AJ, Goldblatt PO. Longitudinal study - Sociodemographic mortality differentials: Series LS 1. Office of Population Censuses and Surveys, Her Majesty's Stationery Office, London 1982.

14. Frost J. Cancerrisikoen blandt stoberiarbejdere 19681972. Arbejdstilsynet, Danish Labour Ministry, Copenhagen.

15. Gibson ES, Martin RH, Lockington JN. Lung cancer mortality in a steel foundry. J occup med 19 (1977) $807-812$.

16. Gibson ES, McCalla DR, Kaiser-Farrell C, Kerr AA, Lockington JN, Hertzmann MD, Rosenfeld JM. Lung cancer in a steel foundry: A search for causation. $J$ occup med 25 (1983) 573-578.

17. Hill ID. Computing man-years at risk. $\mathrm{Br} \mathrm{j}$ prev soc med 26 (1972) 132-134.

18. Kaiser C, Kerr A, McCalla DR, Lockington JN, Gibson ES. Mutagenic material in air particles in a steel foundry. Chem biol eff int symp 4th (1980) 579-588.

19. Koskela RS, Hernberg S, Kärävä R, Järvinen E, Nurminen M. A mortality study of foundry workers. Scand j work environ health 2 (1976): suppl 1, 73-89.

20. Koskela RS, Luoma K, Hernberg S. Turnover and health selection among foundry workers. Scand $\mathrm{j}$ work environ health 2 (1976): suppl 1, 90-105.

21. Kunze $\mathbf{M}$. The risk of lung cancer facing workers in the iron and metal manufacturing industry. Presented at the IIIrd International Colloquium for the Prevention of Occupational Accidents and Diseases in the Iron and Metal Manufacturing Industry, Palma de Mallorca, Spain, 15-16 June 1982. 
22. Lerer TJ, Redmond CK, Breslin PP, Salvin L, Rush AW. Long term mortality study of steelworkers: VII Mortality patterns among crane operators. J occup med 16 (1974) 609-614.

23. Lloyd Davies TA. Respiratory disease in foundrymen: Report of a survey. Her Majesty's Stationery Office, London 1971.

24. McCalla DR, Gibson ES, Kaiser-Farrell C, Kerr A, Sheldrake C, Lockington JN. Analysis of a lung cancer hazard in a steel foundry: Mutagenicity of emissions from eight mould binder systems. J occup med (in press).

25. McKennel AC, Thomas RK. Adults' and adolescents' smoking habits and attitudes. Her Majesty's Stationery Office, London 1967.

26. Neuberger $\mathbf{M}$, Kundi $\mathbf{M}$, Haider $\mathbf{M}$, Grundorfer $\mathbf{W}$. Cancer mortality of dust workers and controls - Results of a prospective study. In: International Labour Office. Prevention of Occupational Cancer: International symposium. Geneva 1982.

27. Office of Population Censuses and Surveys. General household survey 1972. Her Majesty's Stationery Office, London 1975.

28. Office of Population Censuses and Surveys. Occupational mortality, the Registrar General's decennial supplement for England and Wales, 1970-72. Her Majesty's Stationery Office, London 1978.

29. Palmer WG, Moorman W, Stettler L, James R, Scholz R. Analyses of effluents collected from four types of iron casting molds for use in carcinogenesis bioassays. AFS trans 89 (1981) 653-658.

30. Palmer WG, Scott WD. Lung cancer in ferrous foundry workers: A review. Am ind hyg assoc j 42 (1981) 329-
340.

31. Rao CR. Linear statistical inference and its applications. John Wiley, New York, NY 1965.

32. Redmond CK, Wieand HS, Rockette HE, Sass R, Weinberg G. Long-term mortality experience of steelworkers. US Department of Health, Education and Welfare, Cincinnati, $\mathrm{OH} 1981$.

33. Registrar General. Registrar General's decennial supplement, England and Wales 1961: Occupational mortality tables. Her Majesty's Stationery Office, London 1971.

34. Royal College of Physicians. Smoking or health: The third report from the Royal College of Physicians of London. Pitman Medical, London 1977.

35. Schimberg RW, Pfaffli P, Tossavainen A. Polycyclic aromatic hydrocarbons in foundries. $\mathrm{J}$ toxicol environ health 6 (1980) 1187-1194.

36. Tola $S$. Epidemiology of lung cancer in foundries. $\mathbf{J}$ toxicol environ health $6(1980) 1195-1200$

37. Tola S, Koskela RS, Hernberg S, Järvinen S. Lung cancer mortality among iron foundryworkers. J occup med 21 (1979) 753-760.

38. Turner HM, Grace HG. Lung cancer and occupation. J hyg 38 (1938) 90-103.

39. Verma DK, Muir DCF, Cunliffe S, Julian JA, Vogt JH, Rosenfeld J. Polycyclic aromatic hydrocarbons in Ontario foundry environments. Ann occup hyg 25 (1982) $17-25$

Received for publication: 21 October 1983 